\title{
A prática docente na perspectiva freireana: reflexões preliminares
}

\author{
Diego Hellere Ferreira Guedes ${ }^{1}$; Lucas Vieira de Lima Silva² ; Márcia Kelma de Alencar Abreu ${ }^{3}$
}

Resumo: O presente artigo tem como objetivos principais: refletir sobre a prática educativo-progressista defendida por Paulo Freire; compreender a importância de uma formação docente calcada em teorias que favoreçam a autonomia dos educandos; e discutir possibilidades de docentes e discentes assumirem-se como sujeitos transformadores da realidade. Ressaltamos que este trabalho é resultado de estudos iniciais, logo a metodologia adotada foi baseada apenas por meio de uma pesquisa bibliográfica fundamentada em algumas obras do autor, dentre as quais destacamos: Pedagogia do Oprimido e Pedagogia da Autonomia. De natureza qualitativa descritiva. Para ele, o principal objetivo da educação é formar cidadãos conscientes da situação opressora e injusta em que os menos favorecidos se encontram e levá-los a assumirem posturas de engajamento na luta contra a ordem social capitalista. Diante disso, aponta alternativas para a transformação da realidade educacional, enfatizando a necessidade de uma prática educativa e de uma ação crítico-reflexiva entre educadores e educandos, no que concerne ao ensino dos conteúdos escolares e a apropriação de conhecimentos necessários à essa prática. Segundo Paulo Freire, é imprescindível que esses sujeitos adotem atitudes de comparação, intervenção, escolhas, decisões e rompimentos. Portanto, que sejam seres éticos e conscientes da necessidade da transformação da realidade. A prática educativa proposta por Freire é vasta. Por esse motivo, compreendemos o esforço por mais estudos e apropriação desta prática por parte dos educadores e educandos brasileiros.

Palavras - chave: Prática Docente. Educação. Conscientização.

\section{Practice teaching in perspective freirean: preliminary thoughts}

\begin{abstract}
This article has as main objectives: to reflect on the educational and progressive practice advocated by Paulo Freire; understand the importance of teacher education grounded in theories that favor the autonomy of students and discuss possibilities for teachers and students to assume themselves as subjects of reality transformers. We emphasize that this work is the result of initial studies, so the methodology was based only through a literature search based on some works of the author, among which we highlight: Pedagogy of the Oppressed and Pedagogy of Autonomy. Qualitative - descriptive. For him, the main purpose of education is to form citizens aware of the oppressive and unfair situation in which the poor are and get them to assume positions of engagement in the fight against the capitalist social order. Thus, he points out alternatives to the transformation of the educational reality, highlighting the need for educational practice and a critical action - reflective educators regarding the teaching of school subjects and the appropriation of knowledge necessary for the practice. According to him, it is essential that teachers and students adopt attitudes comparison, intervention, choices, decisions and disruptions, so they are ethical beings and aware of the need for transformation of reality. It concludes that educational practice proposed by Freire is vast. Thus, we understand that there is a need for more research and appropriation of this practice by Brazilian educators.
\end{abstract}

Key - words: Teacher training; Educating; Awareness.

\footnotetext{
${ }^{1}$ Graduando em Geografia - Universidade Regional do Cariri - URCA. Email: juazeiro2000@ hotmail.com

${ }^{2}$ Professor do Curso de Educação Física - Universidade Regional do Cariri - URCA. Email: vieira11silva@ hotmail.com

${ }^{3}$ Professora do Curso de Pedagogia - Universidade Regional do Cariri - URCA. Email: kelmabreu@ yahoo.com.br.
} 
Id on Line Revista Multidisciplinar e de Psicoloqia

Id on Line Multidisciplinary Journal and Psycology

\section{Introdução}

\section{Em defesa de uma Pedagogia Crítica}

A prática docente na perspectiva Freireana, no Século XXI, enquanto possibilidade no que seja possível para um Educador de caráter progressista nessa sociedade capitalista, encontra diversos obstáculos decorrentes, ainda, de uma prática educativa bancária disseminada ao longo dos tempos.

Diante dessa configuração, propomos, neste trabalho, refletir sobre a prática educativoprogressista defendida por Paulo Freire; compreender a importância de uma formação docente calcada em teorias que favoreçam a autonomia dos educandos; e, por fim, discutir possibilidades de docentes e discentes assumirem-se como sujeitos transformadores da realidade. Portanto, convidamos à reflexão sobre a coerência da prática educativa tendo em vista a formação libertadora e emancipada dos sujeitos, conscientizando-os de seu papel crítico e interventivo na sociedade.

Justificamos este trabalho levando-se em consideração a necessidade de reflexão permanente e conscientizante da prática pedagógica em prol de uma educação libertadora e transformadora da realidade dos sujeitos oprimidos e opressores.

A problematização nasceu da seguinte pergunta: Como a perspectiva da teoria Freireana contribui para a prática docente no atual sistema educacional que impõem ao ensino uma educação alienante em detrimento de uma formação de sujeitos críticos e conscientes para a transformação da realidade?

A partir da reflexão das principias obras do autor, Pedagogia do Oprimido (2011) e Pedagogia da Autonomia (2014), ressaltamos que o autor propõe um projeto de formação para educadores-educandos enquanto sujeitos pensantes que através da educação para o Ser Mais, direciona, democraticamente, o desenvolvimento de sujeitos que pela aprendizagem dos conhecimentos científicos, tornam-se sujeitos críticos e ativos em seu contexto social.

Freire (2014) expõe que os fundamentos essenciais a uma prática crítico-educativa fundamentam-se na transformação da curiosidade ingênua, para uma curiosidade sistemática, ou seja, crítica da realidade objetiva. Defende o papel do docente como mediador, sujeito este 
Id on Line Revista Multidisciplinar e de Psicoloqia

Id on Line Multidisciplinary Journal and Psycology

que deve ser curioso, inquieto, questionador do mundo em que vive. Sem esta curiosidade não aprende e nem ensina. A ação educativa move-se pela e na curiosidade que possui. A curiosidade ingênua dos seus educandos é a matéria prima para torná-la, no processo educativo, qualitativamente diferente, não mais ingênua ou espontânea como do ponto de partida, mas epistemológica, ou seja, científica e crítica.

Quando o educador respeita a leitura de mundo do educando, reconhece que o saber é histórico e a curiosidade também, assim ele assume uma humildade fundamental na relação com o educando e com o próprio conhecimento. Porém, o educador antidemocrático, não respeita a leitura de mundo do educando, não o escuta e nem com ele dialoga, tornando o mesmo um depósito de suas informações e instruções. Outro aspecto relevante em relação à leitura de mundo do discente é o fato de revelar a inteligência do indivíduo, que se constitui cultural e social.

Freire (2014) expõe que uma das tarefas principais da escola, como espaço-tempo da produção de conhecimentos, é a formação da inteligibilidade e comunicabilidade no processo ensino-aprendizagem. É fundamental que a escola estimule constantemente a curiosidade do educando, e através deste estímulo ele assuma, conscientemente, o papel de sujeito cognoscente no processo de aprendizagem.

A metodologia adotada foi baseada apenas por meio de uma pesquisa bibliográfica fundamentada em algumas obras do autor, dentre as quais destacamos: Pedagogia do Oprimido e Pedagogia da Autonomia. De natureza qualitativa - descritiva.

Este trabalho está organizado em duas partes. Na primeira, realizamos uma discussão reflexiva sobre Paulo Freire e a prática docente no Brasil, dividindo-a na biografia desse teórico, da prática docente em nosso país e as proposições apontadas pela teoria freireana para a educação. E, na segunda, concluímos o trabalho com as considerações finais. 
Id on Line Revista Multidisciplinar e de Psicoloqia

Id on Line Multidisciplinary Journal and Psycology

\section{Paulo Freire e a prática docente no Brasil}

\section{Paulo Freire: Quem Foi Ele?}

Paulo Reglus Neves Freire nasceu em Recife-PE. Desde cedo conheceu a pobreza da Região Nordeste do Brasil. Foi a partir da sua adolescência que se engajou na educação de jovens e adultos trabalhadores e conscientes de suas reais situações, tendo dedicado sua vida à

alfabetização de jovens e adultos. É Patrono da educação brasileira de acordo com a lei $n^{\circ}$ 12.612, sancionada pela Presidenta Dilma Rousseff e pelo Ministro da Educação Aloísio Mercadante em 13 de abril de 2012 (FREIRE, 2012). É considerado um dos maiores intelectuais do século XX, tendo contribuído para a elaboração de perspectivas pedagógicas direcionadas à formação de educadores e educandos críticos. Recebeu de respeitadas Universidades do mundo o Título de Doutor Honoris Causa, sendo o seu livro Pedagogia do Oprimindo um dos mais conhecidos, dedicando a obra aos esfarrapados do mundo. Propôs uma educação que se preocupa com a transformação da realidade por parte das classes dominadas, fazendo-as refletir sobre a condição em que se encontram, apontando para uma atuação modificadora desta sua situação. A partir da sua prática educativa criou um método de alfabetização fundado no principio da educação a partir da realidade que cerca o educando, estimulando assim o diálogo, bem como a reflexão crítica das classes populares.

Segundo Freire (2006), é preciso que a educação seja desveladora da realidade social, levando a compreender qual a posição que os indivíduos ocupam no seu contexto social, quem trabalha para produzir e quem lucra com esse trabalho. Não basta somente ensinar a ler, mas formar pessoas conscientes e criticas, evitando assim uma prática docente bancária e alienante a serviço de um sistema opressor.

\section{Prática docente: perspectivas preliminares}

Como sabemos Paulo Freire contribuiu significativamente para a educação brasileira, compreendendo que as suas reflexões sobre a prática pedagógica são caracterizadas como uma forma de luta por uma educação em favor das classes dominadas. Ele afirma que para a mudança 
Id on Line Revista Multidisciplinar e de Psicoloqia

Id on Line Multidisciplinary Journal and Psycology

dessa realidade, a educação é uma ferramenta fundamental já que o educador pode rever sua ação pedagógica problematizando os conteúdos que na prática tradicional são impostos aos educandos. Essa concepção de educação é denominada por Freire (2005), de educação bancária, que torna o educando um acumulador acrítico de conteúdos.

Nessa perspectiva os conteúdos são dados, transferidos e aceitos passivamente pelos educandos. O ensino tem caráter apenas prático-utilitário e não responde às necessidades sociais da atualidade.

Segundo o autor, a educação bancária configura-se da seguinte maneira:

O educador é o que educa; os educandos, os que são educados; o educador é o que sabe; os educandos, os que não sabem; o educador é o que pensa; os educandos, os pensados; o educador é o que diz a palavra; os educandos, os que a escutam docilmente [...] (FREIRE, 2011, p.82).

Percebemos que à aprendizagem dos conteúdos está limitada ao atendimento de finalidades conteudísticas e de formação dos educandos para o mercado de trabalho capitalista. Segundo Gadotti; Freire; Guimarães (2008, p.119):

[...] Se a fala foi tirada do currículo é porque falar, numa sociedade silenciosa como é a sociedade opressiva, é um ato de subversão. A educação para a fala, para a formação do orador (no sentido daquele que defende seus direitos), seria um suicídio para a sociedade opressiva [...]. Além de ensinar o povo a gritar eu destacaria também a necessidade de os educadores aprenderem a gritar com o povo, no sentido de reivindicar seus direitos $[\ldots]$.

Freire (2011) critica essa ideia de ensino, pois para ele ensinar é possibilitar a criação ou a produção de conhecimentos. Educadores e educandos são coparticipantes do processo ensinoaprendizagem, sendo necessário que estes procurem refletir juntos as finalidades dos conteúdos escolares. Essa atitude implica uma apropriação teórica dos conteúdos como componente fundamental na transformação da sociedade.

Em Pedagogia da Autonomia, Freire (2014), também observa questões fundamentais para a formação de educadores/educadoras. Formação esta, voltada para uma prática onde se favoreça a autonomia dos educandos. Segundo ele, esta autonomia é desenvolvida quando o educador instiga o educando a uma curiosidade epistemológica e a ter uma conscientização da necessidade de se posicionar diante da realidade, superando posturas ingênuas ou astutas em seu contexto social. Também chama a atenção de educadores/as para a responsabilidade ética 
Id on Line Revista Multidisciplinar e de Psicoloqia

Id on Line Multidisciplinary Journal and Psycology

no exercício da atividade docente, pois a ética é necessária à prática educativa enquanto uma prática formadora.

Assim, diz Freire (2014, p. 17): "Educadores e educandos não podemos, na verdade, escapar à rigorosidade ética. Mas é preciso deixar claro que a ética de que falo não é a ética menor, restrita, do mercado, que se curva obediente aos interesses do lucro".

A ética da qual fala o autor não é a ética que serve ao mercado capitalista, mas fala da ética humana que é inerente à prática educativa, seja no trabalho realizado com crianças, jovens ou adultos. É necessário lutar por ela, através da nossa prática docente, na relação que temos com os educandos.

O preparo científico do professor é tão fundamental quanto sua ética. É importante que o educando perceba o respeito e a lealdade do professor, quando este analisa e critica as atitudes dos outros. Não podemos nos considerar sujeitos históricos e transformadores, se não assumirmos uma postura ética para tal. Não podemos aceitar a transgressão de princípios éticos, pois a ética é indispensável à vida humana, como fala o autor:

\footnotetext{
Não podemos nos assumir como sujeitos da procura, da decisão, da ruptura, da opção, como sujeitos históricos, transformadores, a não ser assumindo-nos como sujeitos éticos. Neste sentido, a transgressão dos princípios éticos é uma possibilidade mas não é uma virtude. Não podemos aceitá-la (FREIRE, 2014, p.19).
}

Assumir uma postura ética é uma virtude necessária ao educador. Esta necessidade ética lhe coloca o dever de se preparar, de se formar antes mesmo de iniciar sua atividade docente. Impele para o educador que tenha a consciência de que sua prática pedagógica deve ter como um de seus fundamentos a rigorosidade ética. Este princípio deve nos levar a certeza de que a prática educativa não pode ser um treinamento técnico. Assim, o ensino competente dos conteúdos não deve e nem pode ser distanciado da formação ética dos discentes.

\section{Prática docente: proposições freireanas}

Outro saber fundamental ao educador é a reflexão crítica sobre a prática, pois ao contrário do que muitos pensam, o ato de ensinar não é tão simples. Requer o desenvolvimento de um trabalho docente voltado para uma reflexão sobre o fazer pedagógico. Exige que o 
educador compreenda que sua ação tem uma dimensão além do que ele imagina. Assim, o educador não deve ser um sujeito passivo, que apenas reproduz, mas deve ser um sujeito ativo que atue para a transformação do seu educando, por meio de uma reflexão crítica sobre a prática.

Essa reflexão é fundamental para a relação Teoria/Prática, pois esses dois saberes se completam. Refletir criticamente sobre o trabalho que está sendo realizado em nossas salas escolas é extremamente necessário. Apesar de muitos educadores não terem consciência disso, é a partir desta postura que se fundamenta o seu trabalho.

Uma prática docente crítica compreende a dialética de refletir sobre o que se faz, leva a uma práxis-educativa. $\mathrm{O}$ educador age, reflete sobre sua ação e a partir do que foi refletido suas ações posteriores, indiscutivelmente, contribuirão para uma melhor aprendizagem dos educandos e também para a prática do educador.

Por isso é que, na formação permanente dos professores, o momento fundamental é o da reflexão crítica sobre a prática. É pensando criticamente a prática de hoje ou de ontem que se pode melhorar a próxima prática. O próprio discurso teórico, necessário à reflexão crítica, tem de ser de tal modo concreto que quase se confunda com a prática (FREIRE, 2014, p. 40).

A reflexão crítica da prática suscita um aperfeiçoamento da prática do educador e a superação de uma curiosidade ingênua para uma curiosidade epistemológica por parte do educando. A reflexão crítica incita uma disponibilidade para mudar, e neste sentido, mudar significa desenvolver atitudes de ruptura com as desigualdades, exploração e alienação.

Outro ponto destacado pelo autor é a necessidade de o educando assumir-se como um sujeito da produção do saber e de que o educador (a) se convença de que "ensinar não é transferir conhecimento, mas criar as possibilidades para a sua própria produção ou a sua construção" (FREIRE, 2014, p. 47). Ou seja, ensinar é propiciar meios para o educando se construir, fazer-se, humanizar-se. O processo de formação em ambiente escolar, segundo Freire, é um percurso emancipador, dialógico, de sujeitos e não de objetos. Assim ele nos explica:

É neste sentido que ensinar não é transferir conhecimentos, conteúdos, nem formar é ação pela qual um sujeito criador dá forma, estilo ou alma a um corpo indeciso e acomodado. Não há docência sem discência, as duas se explicam e seus sujeitos, apesar das diferenças que os conotam, não se reduzem à condição de objeto um do outro (FREIRE, 2014, p.25). 
Educador e educando são protagonistas do processo educativo. A importância de um, não reduz à relevância de outro, ambos são sujeitos em funções diferentes, ou seja, o ensino depende da aprendizagem e vice-versa. A validade do ensino resulta quando o educando tornase capaz de recriar o que a ele foi ensinado.

A prática de ensinar-aprender exige uma autenticidade que nos leva a uma experiência de fato diretiva, política, radicalmente democrática. A experiência de aprender é um processo que pode estimular no aprendiz uma curiosidade epistemológica. Essa curiosidade cientificamente-crítica é fundamental, uma vez que é uma recusa ao ensino bancário, citado por Freire (2014), e segundo seu pensamento, esse tipo de ensino deforma a criatividade necessária do educando e do educador.

Respeitar a leitura de mundo do educando significa tomá-la como ponto de partida para a compreensão do papel da curiosidade, de modo geral, e da humana, de modo especial, como um dos impulsos fundantes da produção do conhecimento. É preciso que, ao respeitar a leitura de mundo do educando para ir mais além dela, o educador deixe claro que a curiosidade fundamental à inteligibilidade do mundo é histórica e se dá na história, se aperfeiçoa, muda qualitativamente, se faz metodicamente rigorosa. E a curiosidade assim metodicamente rigorizada faz achados cada vez mais exatos (FREIRE, 2014, p.120).

Dentro da prática educativa, também não se pode deixar de existir o educador democrático, o qual deve estimular a capacidade crítica do educando, sua curiosidade. Para isso, é primordial que o educador ensine aos educandos a necessidade uma rigorosidade metódica para que adquiram conhecimentos.

Nesse sentido, ensinar não é apenas tratar de um objeto ou conteúdo de forma superficial, mas é propiciar condições para uma aprendizagem crítica. Essas condições exigem educadores criadores, instigadores, inquietos, curiosos, humildes e persistentes. Assim, o educador contribui para a formação de educandos que aprendam criticamente e compreendam que esses conhecimentos não podem ser simplesmente transferidos. Pelo contrário, para que ocorra uma verdadeira aprendizagem, o educando precisa ir se transformando em sujeito real da construção e reconstrução do saber ensinado, em que ele, junto com o educador, se perceba como sujeito no processo.

Para o educador progressista coerente, o necessário ensino dos conteúdos estará sempre associado a uma "leitura crítica" da realidade. Ensina-se a pensar certo através do ensino dos conteúdos. Nem o ensino dos conteúdos em si, ou quase em si, como se o contexto escolar em que são tratados pudesse ser reduzido a um espaço neutro 
em que os conflitos sociais não se manifestassem, nem o exercício do "pensar certo" desligado do ensino dos conteúdos (FREIRE, 2006, p. 29).

Desta forma para Freire (2006), não é possível minimizar, desprezar, o "saber de experiência feito" que os educandos trazem do mundo em que vivem para o ambiente escolar, mas rompendo-o para superá-lo, se alcance um saber mais exato, de natureza científica, da realidade que os cercam.

Através do ensino crítico dos conteúdos, o educador procura desocultar os problemas sociais, levando o educando a uma leitura crítica da sua realidade, sendo essa passagem de leitura de mundo, para a leitura da palavra, respeitada pelo educador progressista, evitando assim uma educação conservadora que oculta, aliena e manipula, aos interesses dos opressores.

A essência dessa prática educativa é conscientizar para uma postura inquieta, desafiadora, revolucionária, evitando assim acomodar os educandos ao mundo dado, pelo contrário este pode ser mudado, transformado, reinventado com uma prática educativa que os leve a refletir criticamente, de modo a serem cidadãos em permanente processo de conscientização.

Brandão (2004, p. 106), afirma que:

\begin{abstract}
A educação imposta aparece como ofertada. O interesse político de tornar, também a educação, um instrumento de reprodução da desigualdade e da ocultação da realidade à consciência, aparece como uma questão de trabalho técnico sustentado por princípios de ciências neutras. Assim, a educação que serve, nas mãos do poder que oprime, para ocultar de todos a própria realidade da opressão e para fazer os homens cada vez mais diferentes pelo grau diferenciado de saber que distribui, oculta-se a si mesma.
\end{abstract}

Ainda, de acordo com o pensamento do mesmo autor:

Por isso, a educação libertadora que é, ao mesmo tempo, o sonho e o método de Paulo Freire, é a reflexão dessa prática popular, tornada possível também através da participação do educador: com o seu saber que subverte a intenção de domínio da educação opressora; com os seus recursos colocados a serviço da educação do oprimido (BRANDÃO, 2004, p. 108).

As contribuições das teorias de Paulo Freire no contexto da educação para as classes populares, bem como a prática docente, revelam a importância de uma educação crítico reflexiva, está conscientizadora para a transformação da realidade educacional. Esta prática 
deve romper com o tradicionalismo de uma educação bancária que não forma conscientemente a criticidade de educadores/ educandos, mas serve para melhor manipular e alienar as classes oprimidas, levando-as a não pensar a realidade que as cercam de forma desveladora. A prática docente freireana propõe a libertação dos indivíduos com uma educação humanizadora, crítica por essência. Desta forma elenca que só através da curiosidade epistemológica a educação poderá formar indivíduos conscientes, democráticos, críticos, para assim intervirem e questionarem o mundo em que estão inseridos, procurando conhecer a sua realidade, para transformá-la e assim libertando-se das diversas formas de opressão e alienação.

O educador precisa ser democrático, sabendo a importância do diálogo no processo de ensino - aprendizagem, levando os discentes a buscarem sua autonomia na produção do conhecimento, tornando-se, estes sujeitos pensantes, questionadores do mundo em que vivem, inquietos e curiosos, pois a curiosidade tem papel fundamental na prática educativa. Respeita a leitura de mundo do educando, como ponto de partida para transformá-la em conhecimento científico. O educador democrático problematiza os conteúdos de maneira sistemática, ou seja, crítica da realidade objetiva, o mesmo nega um ensino de depósitos que aliena a realidade e forma cidadãos acríticos, frente ao contexto histórico em que os mesmos se encontram.

Diante dessas reflexões sobre as proposições freireanas frente a realidade educacional, suas teorias revelam a importância, além das já citadas, a uma responsabilidade ética no exercício docente, pois a mesma é necessária enquanto prática formadora de cunho humanizador. "A educação é um ato de amor e, por isso, um ato de coragem. Não pode temer o debate. A análise da realidade. Não pode fugir à discussão criadora, sob pena de ser uma farsa" (FREIRE, 2013, p.127).

\section{Considerações Finais}

Ao defender uma educação que leve a ascensão das classes dominadas, Freire apresenta a relevância de uma formação radicalmente crítica, negadora das injustiças e explorações da sociedade capitalista. Leva-nos a refletir o presente, sob uma perspectiva de transformação da realidade de homens e mulheres. 
Id on Line Revista Multidisciplinar e de Psicoloqia

Id on Line Multidisciplinary Journal and Psycology

Essas transformações só se revelam, através de um conhecimento intencional e sistematizado, de um engajamento consciente e coletivo em um movimento real de transformação da realidade. É neste sentido que o autor ressalta a importância do papel do educador, para que ele desenvolva uma atitude de sujeito pensante e aponte caminhos para que os educandos adquiram criticamente conhecimentos científicos sobre a realidade, partindo da curiosidade ingênua ou informal, para com esta alcançar a curiosidade epistemológica.

É fundamental que o educador investigue, questione e reflita acerca dos conteúdos necessários para a formação de educandos conscientes e conhecedores das mazelas do sistema opressor atual.

Freire (2014), ao analisar uma educação humanizadora como verdadeiramente libertadora, recusa o otimismo ingênuo de uma educação mecanicista, que se enraíza no determinismo histórico que nega o amanhã e o aborda como tempo já determinado. Propõe uma transformação da consciência ingênua para uma crítica, esta última, cientificamente esclarecedora da realidade. Educação humanizada, que coloca os homens como centro de sua análise, para uma ininterrupta consciência destes diante do mundo e esta só acontece com uma educação que faça pensar, dialogar e não memorizar mecanicamente conteúdos escolares.

Através da sua perspectiva educativa, Freire nos leva a refletir sobre a possibilidade de assumirmos uma postura mais ativa e política como educadores e educandos. A educação para a transformação e conscientização, sempre questionadora e curiosa por essência, compreende que a construção e aprendizagem de conhecimentos podem proporcionar que homens e mulheres tornem-se mais humanos.

A nossa percepção a respeito das questões abordadas por Freire nos leva a compreender que esta prática educativa proposta por ele ainda necessita de estudos e da apropriação por parte de muitos educadores brasileiros. Tendo em vista que esta é uma tarefa que exige do educador uma esperança crítica pela transformação da educação, e que a prática do educador é conscientizadora, ele precisa mobilizar os educandos para que assumam suas capacidades de compreensão de mundo e de intervenção transformadora da realidade. 
Id on Line Revista Multidisciplinar e de Psicoloqia

Id on Line Multidisciplinary Journal and Psycology

\section{Referências}

BRANDÃO, Carlos Rodrigues. O que é Método Paulo Freire. São Paulo: Brasiliense, 2004.

FREIRE, Paulo. A educação na cidade. Ed. 7. São Paulo: Cortez, 2006.

Pedagogia do Oprimido. Ed. 50. Rio de Janeiro: Paz e terra, 2011.

À sombra desta Mangueira. Ed. 10. Rio de Janeiro: Civilização Brasileira, 2012.

Educação Como Prática da Liberdade. Ed. 15. Rio de Janeiro: Paz e Terra, 2013.

Pedagogia da Autonomia: saberes necessários à prática educativa. Ed. 48. Rio de Janeiro: Paz e terra, 2014.

GADOTTI, Moacir; FREIRE, Paulo; GUIMARÃES, Sérgio. Pedagogia: Diálogo e Conflito. Ed. 8. S Paulo: Cortez, 2008.

Como citar este artigo (Formato ABNT):

GUEDES, D.H.F.; SILVA, L.V L.; ABREU, M.K.A. A prática docente na perspectiva freireana: reflexões preliminares. Id on Line Revista Multidisciplinar e de Psicologia, Set-Out/2016, vol.10, n.31, Supl 1. p. 255266. ISSN 1981-1179.

Recebido: 20/08/2016.

Aceito: $25 / 08 / 2016$ 